\title{
Financial Burden and Health-seeking Behaviors Related to Chronic Diseases Under the National Health Insurance Scheme in Bolikhamxay Province, Lao PDR: A Cross-sectional Study
}

TOMOO ITO ( $\nabla$ t-itot@it.ncgm.go.jp )

National Center for Global Health and Medicine

Sengchanh Kounnavong

Lao Tropical and Public Health Institute

Chiaki Miyoshi

National Center for Global Health and Medicine

\section{Research Article}

Keywords: chronic disease, finances, health behavior, health insurance, universal health coverage

Posted Date: December 15th, 2021

DOl: https://doi.org/10.21203/rs.3.rs-885719/v2

License: (c) (i) This work is licensed under a Creative Commons Attribution 4.0 International License. Read Full License 


\section{Abstract}

\section{Background}

Financial protection is a key dimension of universal health coverage. In 2016, Lao PDR implemented a National Health Insurance system covering the entire population of certain provinces. This cross-sectional study investigated the health-seeking behavior and financial burden of households, including those with chronic patients, post coverage.

Method

The study was conducted in Bolikhamxay province from January 15 to February 13, 2019. In total, 487 households, selected via stratified random sampling, were surveyed, and questionnaire-based interviews were conducted. Health care service utilization and financial burden were examined.

Results

A total of 370 households had at least one member with some type of self-reported health problem within the last 3 months prior to the interview, while 170 had at least one member with a chronic condition. More than $75 \%$ of the households accessed a health facility when a member experienced health problems. The prevalence of catastrophic health expenditure (health expenditure/income between $20 \%$ and $40 \%$ ) was $25.1 \%$ (threshold of $20 \%$ ) and $16.2 \%$ (threshold of $40 \%$ ). Through logistic regression, we found that the major factors determining financial catastrophes owing to health problems were household members with chronic illness, hospitalization, household poverty status, family size (both $20 \%$ and $40 \%$ thresholds), visiting a private facility ( $20 \%$ threshold), and distance from the province to the referral hospital ( $40 \%$ threshold).

\section{Conclusions}

The National Health Insurance system has positively impacted households' access to health facilities. However, catastrophic health expenditure remains high, especially among chronic patients. Facilities under the National Health Insurance should be strengthened to provide more services, including care for chronic conditions.

\section{Background}

Universal health coverage (UHC) is a key health target outlined in the United Nation's Sustainable Development Goals (SDGs) [1]. UHC is defined as a system in which all individuals and communities receive health services without suffering financial hardship; this includes the full spectrum of essential and quality health services, ranging from health promotion to prevention, treatment, rehabilitation, and palliative care [2]. Many countries are working to achieve UHC. In this context, financial protection plays a particularly important role [1-4]. Specifically, ensuring individuals are protected from the financial consequences of paying for health services out-of-pocket (OOP) helps to reduce the risk of poverty. This is because an 
unexpected illness may require the use of an individual's life's savings, assets, or loans, with likely disastrous consequences for their future wellbeing.

Timely access to and affordable health care is a widespread challenge; reports show that 1.3 billion people worldwide are unable to access affordable and effective health care services [5]. Even among households with such access, approximately 170 million individuals are forced to spend more than $40 \%$ of their income on medical treatment, forcing them into catastrophic health expenditure (CHE) situations [5]. Such situations occur when the ratio of medical care expenses to income is significantly high, and might force a household into financial poverty by exhausting their savings, incurring large debts, or selling personal property to receive treatment. The government of Lao PDR has attempted to address these issues and facilitate the achievement of UHC through the implementation of a National Health Insurance (NHI) system, which was launched in certain provinces in 2016 [6], and may soon be expanded to all provinces.

Before the NHI, Lao PDR had public health insurance schemes such as the State Authority for Social Security for government staff, the Social Security Organization for active workers, the Health Equity Fund for some categories of poor people, and the voluntary Community-Based Health Insurance for the informal sector, such as self-employed people and farmers. However, these schemes have resulted in a fragmented health insurance system, limiting coverage and implementation. For example, the Community-Based Health Insurance and Health Equity Fund has so far covered only about $12 \%$ of their 3.21 million and 192,000 target populations, respectively [7]. To overcome these problems and to realize UHC, the $2016 \mathrm{NHI}$ scheme covering 17 provinces was devised by merging the disparate schemes [6]; it is meant to ultimately cover the entire nation, except for the capital city of Vientiane.

Under the $\mathrm{NHI}$, the payment system for health services has been simplified; health care visits require only a small, fixed, co-payment at the facility level, regardless of the administered treatment. For instance, outpatients at provincial hospitals (referral hospitals), district hospitals, and health centers must submit flat co-payments of 15,000 LAK, or 1.7 US \$, 10,000 LAK (1.13\$), and 5,000 LAK (0.56\$), respectively. For inpatients, the co-payments at both provincial and district hospitals amount to 30,000 LAK (3.5\$) and 5,000 LAK ( 0.56 \$), respectively, at health centers. The NHI package officially includes a range of services, such as acute and long-term care, even palliative care, and there are no cost limitations.

However, the health problems of the general population are diverse, ranging from relatively simple and short-lived diseases to life-threatening ones, and the latter are likely to require a certain level of advanced medical care and long-term treatment. Moreover, although the $\mathrm{NHI}$ officially covers all types of treatment, medications prescribed to patients may not be directly available at their preferred facilities, due to supply shortage or because these are not covered by the NHI. This means that $\mathrm{NHI}$ patients may often need to cover the costs of accessing medication at private pharmacies.

Internationally, disabilities have become a large component of disease burden and health expenditure [8]. Chronic diseases (e.g., major non-communicable diseases [NCDs] such as cardiovascular diseases, cancer, chronic respiratory diseases, and diabetes) can often cause disabilities, posing serious threats to health and longevity. The burden of such diseases is more serious in low- and middle-income countries than in 
high-income countries because of greater challenges in appropriate treatment, prevention, and early detection [9-11]. As chronic diseases need to be treated over a long time, the ensuing financial burden is often worse than that for non-chronic diseases that can be commonly treated over short periods.

Furthermore, chronic patients have a higher risk of developing a comorbid disease, worsening their health condition with time [9].

Several studies based in Lao PDR have reported a high prevalence of morbidity, and of chronic diseases [12-15]; however, no study has examined the health-seeking behavior of the population once they have been diagnosed with an illness, especially a chronic one. Furthermore, there is a lack of academic information on health-seeking behaviors post NHI. We deem such data as very important because the main purpose of the $\mathrm{NHI}$ is to improve people's access to health facilities, while ensuring that they do not suffer CHE. Therefore, if this objective is not even partially achieved, the NHI may be deemed ineffective. For example, although households may not be incurring $\mathrm{CHE}$, if we uncover data that concomitantly show people being unable to access a health facility for treatment, it means that their health is likely to worsen, and the $\mathrm{NHI}$ is not helping. We also see a particular lack of information in the literature regarding the health-seeking behaviors and the financial burden of chronic patients in Lao PDR.

There have been some studies aimed at investigating the impacts of the NHI in Lao PDR [16, 17], but data on health access status and $\mathrm{CHE}$ for households covered by the $\mathrm{NHI}$ are hard to find, which uncovers another research gap3/4this is especially true of households with chronic patients. To bridge these gaps, this study aimed to clarify the health-seeking behaviors, the prevalence of $\mathrm{CHE}$, and the influencing factors of CHE among households, including those with chronic patients, in Bolikhamxay province. We chose this province because the $\mathrm{NHI}$ had been operating there for more than 2 years. To help support the achievement of $\mathrm{NHI}$ goals nationwide, this study aimed at providing data that would clarify the potential pathways to more well-informed decision-making among stakeholders and policymakers on improving health insurance coverage and affordability

\section{Methods}

\section{Study design, area, and sampling method}

Using a cross-sectional design, we investigated the prevalence of health problems in households in Bolikhamxay province in the past 3 months, and their health-seeking behavior and related financial burden. According to the latest data from this province, its total population is 273,691 and it covers an area of $14,863 \mathrm{~km}^{2}$ (or $5,739 \mathrm{mi}^{2}$ ), with a population density of $18 / \mathrm{km}^{2}$ [18]. It shares borders with Xiengkhouang province to the northwest, Vietnam to the east, Khammouane Province to the south, and Thailand to the west. Bolikhamxay province contains 7 districts (Pakxanh, Thaphabath, Pakkading, Borikhan, Viengthong, Xaychamphone, and Khamkeuth), with one provincial hospital, six district hospitals, and 40 health centers [19]. Researchers well-trained in interviewing procedures conducted questionnaire-based interviews with the selected households from January 15 to February 13, 2019.

\section{Sample size and household selection process}


The sampling unit was a household, defined as a group of individuals living together, usually parents and children, and sometimes grandparents and uncles. To calculate the acceptable sample size of households for this study, we referred to a previous study on CHE conducted in Vietnam, a neighbor with a similar political system, which showed CHE prevalence of $20 \%$ threshold of $17.4 \%$ (in 2004) [20]. We also considered margin of error $\mathrm{e}= \pm 5$, critical value at $99.00 \%$ confidence level, and $Z=2.57$, and the total number of households in Bolikhamxay province to be 54,738-a number achieved by dividing the total population $(273,691)$ [18] by the average number of members in a household $(5)$ [21]. This yielded a sample size of 384 households. To address the possibility of withdrawal, approximately $25 \%$ of the households were added to the required sample size, resulting in a final required sample size of 480 households.

$$
\text { Sample size, } \mathrm{n}=\mathrm{N} * \frac{\frac{Z^{2} * p *(1-p)}{e^{2}}}{\left[N-1+\frac{Z^{2} * p *(1-p)}{e^{2}}\right]}
$$

Where the margin of error, $\mathrm{e}= \pm 5$,

Critical value at $95 \%$ confidence level, $Z=1.96$,

Number of households in province, $\mathrm{N}=54,738$, and

Estimated proportion of households in $\mathrm{CHE}, \mathrm{p}=17.4 \%$

Using a stratified systematic sampling method, we selected households as follows. First, we selected three districts, including the provincial capital district (Pakxan). The other two were chosen based on their distance (in km.) from the provincial capital district; the first, Thaphabad, was $50 \mathrm{~km}$ away, and the second, Pakkading, about 70-100 km away. Second, based on how rural areas were defined in the data from the national statistical office, we randomly selected five villages in each district: one urban village, two rural villages with roads, and two rural villages without roads. Third, we randomly selected households (32-33 households in each village) using the village registration book, with equal intervals on the lists. To ensure the minimum sample size acceptable for this paper, upon not acquiring sufficient valid responses from the first group of selected households, we conducted a novel batch of interviews with the next households on the list, and this procedure was repeated until we reached valid responses from 32 households per village.

\section{Definitions}

Chronic disease. Prior research finds that differences in the conceptualization of the term "chronic disease" occur largely based on research data and the discipline of the lead authors [22]. Because we wanted to focus our investigation on all diseases that involved relatively longer treatment periods (to analyze their possible financial burden), regardless of disease course, we chose to simplify its definition. Specifically, a chronic disease in this study entails a patient having the same disease diagnosis for more than three months at the time of the survey [23]. In this study, we classified diseases into chronic and non-chronic diseases, simply by the length of the chronic condition. 
Catastrophic health expenditure (CHE) is defined as a household's medical expenditure exceeding a certain level of capacity to pay. In this study, to calculate $\mathrm{CHE}$, we adapted the proportionality of income approach [24], where we consider the total monthly OOP spending as a proportion of monthly income, or the proportion of household OOP spending for health care greater than the CHE configured in pre-specified proportions. However, a literature review showed a lack of consensus regarding proportion thresholds to configure CHE; specifically, we observed thresholds varying from $5 \%$ to $40 \%$ of total household income [2527]. While there is no final consensus on the choice of the threshold for CHE, for this paper, we employ the more frequently used threshold proposed by K. Xu et al. who define health expenditure as catastrophic if a household's financial contributions to health equals and/or exceed $40 \%$ of nonfood expenditure or capacity to spend [27]. However, Rashidian et al. contend that the appropriate cut-off points for the proportion of OOP health expenses to total expenditure and proportion of health expenditure to ability to pay is $20 \%$ of total expenditure [28]. Applying these two previous studies, we set a health care expenditure of $20 \%$ of the total household income as a threshold for CHE and an expenditure of $40 \%$ as a threshold for serious CHE.

\section{Structure of Questionnaire and independent variables}

The questionnaire was developed by drawing on a number of studies about CHE, health care utilization, and chronic disease [29-35] and on prepared questions from previous household surveys [32-35] appropriately revised for Lao PDR. We divided the questions into seven sections: a) household composition and demography (total monthly income, education level of the household head, and the distance between the household and the nearest medical facility); b) self-reported health problems of household members in the last 3 months: questions in this section were designed with the intention of including a variety of health issues from mild to severe, including injury, for 3 months, following a previous study [36]; c) health-seeking behavior including self-medication and care utilization used by any household member during last 3 months, which provided information for each household member who had a medical consultation in the last 3 months; and e) services used and associated costs for illnesses that occurred prior to the interview in last 3 months. Total health expenditure was the sum of all spending on medicines, transportation to and from health facilities, consultation and treatment costs, laboratory test and diagnostic fees, hospitalization fees, cost of visits to traditional healers, and other health-related expenditures during the last three months converted to four weeks following a previous study [24]. To finalize the questionnaire, the pilot study was implemented for 100 households in Khammouane province, adjacent to the south of Borikamsai Province, to evaluate the accuracy, rigor, and communicability of the answers to the questions.

In our study, following previous studies, total household income level was defined according to the survey questionnaire and categorized into Richest, Rich, Poor, and Poorest by dividing all households into four equal groups, in descending order of income. The education level of the head of the household was defined according to the survey questionnaire and categorized into under or above primary education. Household size was defined as the number of individuals in a household and was recoded as less than five members and more than five members. Place of residence was defined by the distance from the health facilities because we wanted to focus on the access to a health facility and grouped the distance from the nearest

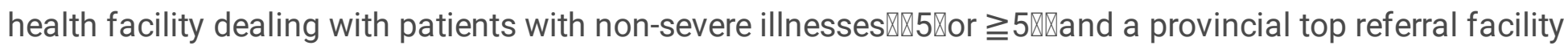


dealing with patients with more severe illnesses ( $<10 \mathrm{~km}$ or $\geqq 10 \bigotimes)$. The type of facility visited was defined according to the survey questionnaire and recoded as public and private health facility. The type of illness suffered was also defined according to the survey questionnaire and recoded as chronic and non-chronic illness.

\section{Data analysis}

SPSS $^{\text {TM }}$ version 25 (IBM Corp., Armonk, NY, USA) was used for statistical analysis. A descriptive analysis was undertaken to understand household background, occurrence and type of health problems, healthseeking behavior in a household unit and an individual unit, and OOP payments in a household. Chi-square statistics were used to compare non-chronic and chronic patients on demographic variables, different income groups for health-seeking behavior, and the different types of facility they used for CHE. MannWhitney $t$ test was used to compare OOP between the different types of facility used. A logistic regression (logit) model was used to predict probability of CHE. Based on the literature, we first assumed that households with $\mathrm{CHE}$ are affected by type of illness and treatment episodes. The variable treatment episodes included all types of care-seeking, from self-medication to health institution care. We expected that chronic illness, hospitalization, treatment in a private facility, treatment, and treatment in a provincial top referral hospital would be associated with high health care expenses. The second group of variables were household characteristics, which included household size, education of the head of household, and distance from the nearest health facility and the top referral hospital in the province. We also included household's economic status (measured by quintile group of monthly income) [36, 37, 38]. All these variables were entered in the logit model, using forward stepwise entry function in the SPSS software; if the probability of its score statistic was less than 0.05 , a variable was included, and removed if the probability was greater than 0.1 . The stepwise entry-removal of the various explanatory variables allowed identifying those that had statistically significant influence on the probability of determining CHE. The following variables were included in the model as categorical variables: a) households with expenditure for treating chronic illness and hospitalization (threshold $20 \%$ and $40 \%$ ), b) households in which at least one member visited a private facility (threshold $20 \%$ ), c) income quintile groups (threshold $20 \%$ and $40 \%$ ), and d) geographical location of household distance from top referral provincial hospital (threshold $40 \%$ ) and the household size. The probability of CHE was calculated with the logit model [39] and the model goodnessof-fit was assessed by the Hosmer-Lemeshow test [40].

\section{Results}

\section{Household demographics and disease prevalence}

All of the 487 households in Bolikhamxay province that were surveyed agreed to being interviewed. Of the 487 households, 370 (76.7\%) had at least one family member with a health problem in the past three months. Among these, 170 (35.7\%) households had at least one person with a chronic condition (Table 1, Figure 1). 
In our sample, 292 (84.3\%) of the households with a health problem in the last 3 months visited a health facility, while households in higher income groups tended to use a medical facility (more than $85 \%$ ) and showed a statistically significant difference $(P=0.039$; Table 2$)$; households that self-medicated tended to be higher in the lower income group $(p<0.0001)$. However, even in the lowest income group, more than $75 \%$ of the households had experienced a health facility visit (Table 2). Specifically, 205 (55.7\%) households had at least one member who had visited a public facility and 75 (20.3\%) households had one member who had visited a private facility. Among the households that visited a private facility, $32(8.6 \%)$ had at least one member who visited a health facility in a foreign country. Moreover, 117 (31.6\%) of the households had at least one member admitted to a hospital for more than one night (Table 1).

Table 1. Household demographics, disease prevalence, and health-seeking behaviors 


\begin{tabular}{|c|c|c|}
\hline & $\begin{array}{l}\mathrm{N} \text { (\% in total } \\
\text { households) }\end{array}$ & $\begin{array}{l}\mathrm{N} \text { (\% in households with at } \\
\text { least one family with health } \\
\text { problem) }\end{array}$ \\
\hline Total household income per month & $\mathrm{N}=487$ & $\mathrm{~N}=370$ \\
\hline $\begin{array}{l}\text { Poorest ( } 25 \%) \text { under } 1000000 \text { kip }(113.3 \\
\text { US\$)/month }\end{array}$ & $140(28.7 \%)$ & $98(28.1 \%)$ \\
\hline $\begin{array}{l}\text { Poor (25\%) } 1000000 \text { kip (113.3 US\$) - } 2000000 \text { kip } \\
(226.6 \text { US\$)/month }\end{array}$ & $112(23.0 \%)$ & $86(24.6 \%)$ \\
\hline $\begin{array}{l}\text { Rich ( } 25 \%) 2000000 \text { kip (226.6 US\$) - } 3500000 \text { kip } \\
\text { (396.7 US\$)/month }\end{array}$ & $102(20.9 \%)$ & $70(20.1 \%)$ \\
\hline Richest (25\%) above 350000 kip (396.7 US\$)/month & $109(22.4 \%)$ & $95(27.2 \%)$ \\
\hline \multicolumn{3}{|l|}{ Total number of household members } \\
\hline $1-4$ & $277(58.8 \%)$ & $192(51.9 \%)$ \\
\hline More than 5 & $210(42.1 \%)$ & $178(48.1 \%)$ \\
\hline \multicolumn{3}{|l|}{ Education of the household head } \\
\hline Primary education & $242(49.7 \%)$ & $186(55.7 \%)$ \\
\hline Above secondary education & $200(41.0 \%)$ & $1149(43.4 \%)$ \\
\hline \multicolumn{3}{|l|}{ Distance from the nearest health facility } \\
\hline$<5 \mathrm{~km}$ & $360(73.9 \%)$ & $276(74.6 \%)$ \\
\hline$\geqq 5 \mathrm{~km}$ & $127(26.1 \%)$ & $94(25.4 \%)$ \\
\hline \multicolumn{3}{|l|}{$\begin{array}{l}\text { Distance from the provincial hospital (top referral } \\
\text { hospital) }\end{array}$} \\
\hline$<10 \mathrm{~km}$ & $95(19.8 \%)$ & $78(21.2 \%)$ \\
\hline$\geqq 10 \mathrm{~km}$ & $392(80.5 \%)$ & $292(78.9 \%)$ \\
\hline $\begin{array}{l}\text { Households with at least one member with any self- } \\
\text { reported health problem }\end{array}$ & $370(76.0 \%)$ & $370(100 \%)$ \\
\hline $\begin{array}{l}\text { Households with at least one member with a } \\
\text { communicable disease }\end{array}$ & $241(44.5 \%)$ & $241(65.1 \%)$ \\
\hline $\begin{array}{l}\text { Households with at least one member with a main } \\
\text { NCD }\end{array}$ & 45 (9.2\%) & $45(12.1 \%)$ \\
\hline $\begin{array}{l}\text { Households with at least one member with other } \\
\text { NCDs }\end{array}$ & $132(47.6 \%)$ & 132 (35.7\%) \\
\hline $\begin{array}{l}\text { Households with at least one member with a chronic } \\
\text { disease }\end{array}$ & 170 (34.9\%) & 170 (46.0\%) \\
\hline $\begin{array}{l}\text { Households with at least one member that visited } \\
\text { any health facility }\end{array}$ & $292(60.0 \%)$ & 292 (78.8\%) \\
\hline
\end{tabular}


Households with at least one member that visited any public facility

Households with at least one member that visited a provincial top referral hospital

Households with at least one member that visited a private facility (including foreign facility) for treatment

Households with at least one member that visited a foreign facility for treatment

Households with at least one member that was admitted to the hospital for more than one night
$205(42.9 \%) \quad 205(55.4)$

$51(10.2 \%) \quad 51(13.8 \%)$

$75(15.4 \%) \quad 75(20.3 \%)$

$32(6.6 \%)$

$32(8.6 \%)$

$117(24.0 \%)$

$117(31.6 \%)$

Table 2. Percentage of households who had visited a health care facility and self-medicated when a family member had a health problem, by household income

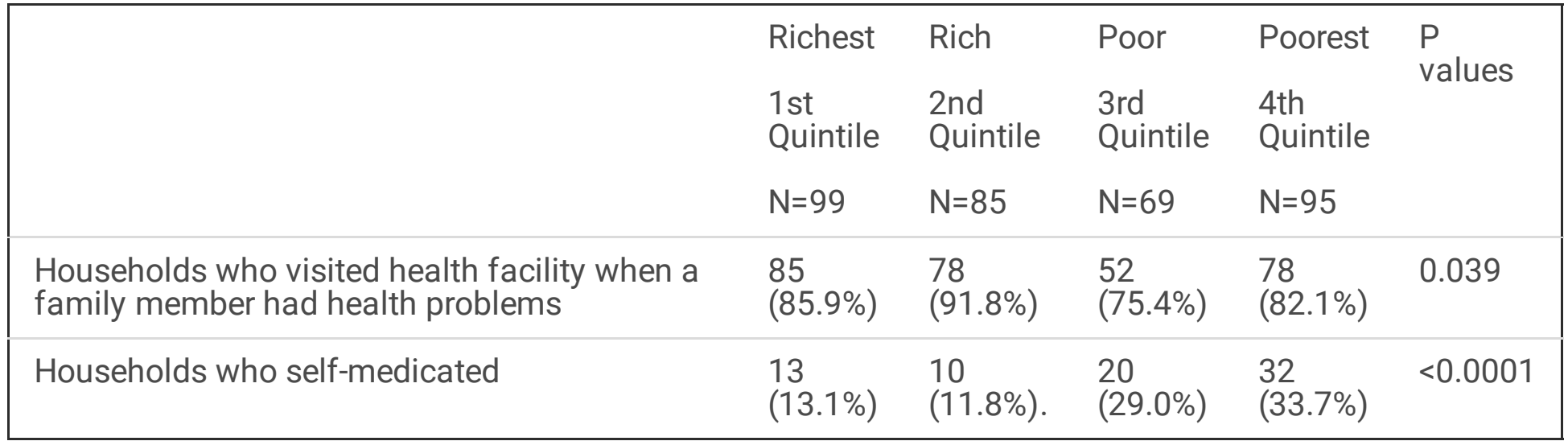

Distribution of total monthly household health expenditure and monthly health cost/monthly income (\%)

Medium OOP health expenditure per month was 100.000 LAK (11.3\$) [interquartile range, 25.000 LAK (2.8\$) to 423.750 LAK (47.9 \$)]. Most households (56.9\%) spent 30,000 LAK (3.4\$) on health per month, which is the maximum value covered by the NHI. The distribution of the other expenditure values was polarized; in the second largest group, households spent more than 300,000 LAK (34.0 \$) on health per month, which is 10 times the maximum value covered by the $\mathrm{NHI}(16.2 \%$, Figure 2$)$. The OOP health expenditure between households that used public facility only for treatment [60.000 LAK (6.8 \$) (interquartile range, 20.000 LAK (2.3 \$) to 250.000 LAK (28.3 \$)] and others (e.g., visiting private facility, self-medication) [160.000 LAK (18.1 \$) (interquartile range, 50.000 LAK (5.3 \$) to 762.500 LAK) (86.4 \$)] was statistically different $(P<0.0001$; Table 3$)$.

\section{Figures 2 and 3 about here}

Regarding CHE, 96 (25.1\%) households met the requirement for $\mathrm{CHE}(20 \%)$ and 60 (16.1\%) met the requirement for $\mathrm{CHE}(40 \%)$. Households with $\mathrm{CHE}$ that used public facility only for treatment were statistically different $(p<0.0001)$ from others (Table 3$)$. A total of 367 households $(75.4 \%)$ had the highest total OOP health expenditure/income ratio of less than $20 \%$. This was followed by 36 households (7.4\%) in 
the $20 \%-40 \%$ OOP expenditure/income ratio. The third largest group of households, 28 (5.7\%), had an OOP expenditure /income ratio of more than $100 \%$ (Figure 3 ).

Table 3. Out-of-pocket payment and catastrophic health expenditure prevalence comparison between households that visited public facilities and those that used other facilities for treatment

\begin{tabular}{|lllll|}
\hline & Total & $\begin{array}{l}\text { Households that visited only } \\
\text { public facilities (health center, } \\
\text { district hospital, provincial } \\
\text { hospital) for treatment } \\
\mathrm{N}=189\end{array}$ & $\begin{array}{l}\text { Households that } \\
\text { used private } \\
\text { facility, including } \\
\text { self-medication }\end{array}$ & values \\
\hline $\begin{array}{l}\text { Out-of-pocket health } \\
\text { expenditure per } \\
\text { month (interquartile } \\
\text { range) (LAK) }\end{array}$ & $\begin{array}{l}100.000 \\
\text { (interquartile } \\
\text { range, } \\
25.000 \text { to }\end{array}$ & $\begin{array}{l}60.000 \text { (interquartile range, } \\
20.000 \text { to 250.000) }\end{array}$ & $\begin{array}{l}\text { 160.000 } \\
\text { (interquartile } \\
\text { range, 50.000 to } \\
762.500)\end{array}$ & $<0.0001$ \\
$\begin{array}{l}\text { Out-of-pocket health } \\
\text { expenditure/income } \\
\text { threshold 20\%) }\end{array}$ & $96(25.9 \%)$ & $39(20.0 \%)$ & $57(35.0 \%)$ & $<0.0001$ \\
\hline $\begin{array}{l}\text { Out-of-pocket health } \\
\text { expenditure/income } \\
\text { (threshold 40\%) }\end{array}$ & $60(16.2 \%)$ & $21(11.1 \%)$ & $39(23.9 \%)$ & $<0.0001$ \\
\hline
\end{tabular}

\section{Household health-seeking behavior}

\section{Differences between chronic and non-chronic patients regarding health-seeking behavior and demographics}

The 487 surveyed households had a total of 2,692 members. Among these, 375 (13.9\%) members reportedly experienced health problems in the past three months, and $198(7.4 \%)$ had a chronic disease. In both groups (i.e., chronic vs. non-chronic patients), around $41.9 \%$ non-chronic and 40.9 chronic members were male. Regarding age, chronic patients were older than non-chronic patients, and the difference was statistically significant (medium [25\%-75\%]; 56 [46-62], 33 [8-54]; $p<0.0001$ ).

The percentage of non-chronic patients $(40.0 \%)$ that visited health centers for treatment was higher than that of chronic patients $(10.6 \%)$, and the difference was statistically significant $(p<0.001)$. The percentage of chronic patients $(34.8 \%)$ that visited the provincial top referral hospital for treatment was higher than that of non-chronic patients $(7.7 \%)$, and the difference was statistically significant $(p<0.0001)$. The percentage of chronic patients (18.6\%) that visited private facilities for treatment was higher than that of non-chronic patients (14.4\%), and the difference was not statistically significant ( $P=0.19$; Table 4).

Table 4. Individual comparison between non-chronic patients and chronic patients for demographic variables 


\begin{tabular}{|llll|}
\hline & Non-chronic patients & Chronic patients & P values \\
\hline Age & $\mathrm{N}=375$ & $\mathrm{~N}=198$ & \\
\hline Sex & $33[8-54]$ & $56[46-62]$ & $<0.0001$ \\
\hline Male & & & 0.82 \\
\hline Female & $157(41.9 \%)$ & $81(40.9 \%)$ & \\
\hline What did they do for the problem? & $218(58.1 \%)$ & $117(59.1 \%)$ & \\
\hline Did nothing & $30(8.0 \%)$ & $0(0.0 \%)$ & $<0.0001$ \\
\hline Took care of themselves & $83(22.1 \%)$ & $42(21.2 \%)$ & 0.80 \\
\hline Visited a health center & $150(40.0 \%)$ & $21(10.6 \%)$ & $<0.0001$ \\
\hline Visited a district hospital & $41(10.9 \%)$ & $37(18.7 \%)$ & 0,01 \\
\hline Visited a provincial top referral hospital & $29(7.7 \%)$ & $69(34.8 \%)$ & $<0.0001$ \\
\hline Visited a private facility & $54(14.4 \%)$ & $37(18.6 \%)$ & 0.19 \\
\hline
\end{tabular}

\section{Catastrophic health expenditure influencing factors}

The logistic regression analysis yielded a wide range of determinants associated with an increased risk of incurring CHE (Table 6,7). It revealed that the odds of facing CHE were 3.773 [CI95\% 2.081-6.8441, $\mathrm{p}<0.0001$ ] (threshold 20\%) and 4.430 [Cl95\% 2.177-9.016, $\mathrm{p}<0.0001$ ] (threshold 40\%), and [Cl95\% 1.4044.667, $\mathrm{p}<0.0001$ ] (threshold 20\%) and 3.405 [Cl95\% 1.721-6.738, $\mathrm{p}<0.0001$ ] (threshold 40\%) times higher among households that had incurred expenditures on treating chronically diseased persons and those that had a case of hospitalization, respectively. Households in the richest quintile were 3.972 [Cl95\% 1.8078.730, $p=0.0001$ ] (threshold 20\%), and 3.339 times [CI95\% 1.264-8.819, $p=0.015$ ] (threshold $40 \%$ ) less likely to face $\mathrm{CHE}$ when compared with the poorest quintile; thus, as household monthly income increased, the probability of facing catastrophic health expenditure declined. Finally, the odds of facing CHE were 2.490 [CI95\% 1.323-4.667, $\mathrm{p}=0.005]$ times higher for the households that received treatment in private facility (threshold 20\%), and 2.669 [CI95\% 1.688-13.558] times higher for households more than $10 \mathrm{~km}$ away from the provincial hospital (threshold 40\%). Households with less than 5 members were 2.112 [Cl95\% 1.1733.803, $p=0.013$ ] (threshold 20\%) and 2.669 [CI95\% 1.688-13.558, $p=0.006$ ] (threshold 40\%) times more likely to incur CHE (Table 5, Table 6).

Table 5. Estimated coefficients in logit model for CHE (threshold 20\%) (Household level data) 


\begin{tabular}{|c|c|c|c|c|c|}
\hline \multirow[t]{2}{*}{ Variable } & \multirow[t]{2}{*}{ B } & \multirow[t]{2}{*}{ Wald } & \multirow[t]{2}{*}{$P$ value } & \multirow[t]{2}{*}{$\begin{array}{l}\text { Odds } \\
\text { ratio }\end{array}$} & \multirow{2}{*}{$\begin{array}{l}\mathrm{Cl} \\
95.0 \% \\
\text { for } \\
\text { Odds } \\
\text { Ratio }\end{array}$} \\
\hline & & & & & \\
\hline $\begin{array}{l}\text { Household with at least one member with a } \\
\text { chronic disease }\end{array}$ & 1.314 & 18.703 & $<0.0001$ & 3.720 & $\begin{array}{l}2.051- \\
6.704\end{array}$ \\
\hline $\begin{array}{l}\text { Household with at least one member admitted to a } \\
\text { hospital for more than one night }\end{array}$ & 0.93 & 9.215 & 0.002 & 2.535 & $\begin{array}{l}1.390- \\
4.620\end{array}$ \\
\hline $\begin{array}{l}\text { Household with at least one member who visited a } \\
\text { private facility for treatment }\end{array}$ & 0.903 & 7.831 & 0.005 & 2.466 & $\begin{array}{l}1.310- \\
4.640\end{array}$ \\
\hline Richest quintile (Reference group) & & 14.936 & 0.002 & & \\
\hline 2nd quintile & 0.148 & 0.105 & 0.746 & 1.160 & $\begin{array}{l}0.473- \\
2.845\end{array}$ \\
\hline 3rd quintile & 0.946 & 5.476 & 0.019 & 2.576 & $\begin{array}{l}1.165- \\
5.688\end{array}$ \\
\hline 4th quintile & 1.387 & 11.923 & 0.001 & 4.002 & $\begin{array}{l}1.821- \\
8.792\end{array}$ \\
\hline Household size $<5$ & 0.755 & 6.338 & 0.012 & 2.127 & $\begin{array}{l}1.182- \\
3.829\end{array}$ \\
\hline Log likelihood & 304.877 & & & & \\
\hline Pseudo R2 & 0.166 & & & & \\
\hline Hosmer-Lemeshow test & $\begin{array}{l}x 2(8)= \\
5.085\end{array}$ & & & & \\
\hline & $P=0.748$ & & & & \\
\hline Observations & 312 & & & & \\
\hline
\end{tabular}

Table 6. Estimated coefficients in Logit model for CHE (threshold 40\%) (Household level data) 


\begin{tabular}{|c|c|c|c|c|c|}
\hline Variable & B & Wald & $P$ value & $\begin{array}{l}\text { Odds } \\
\text { ratio }\end{array}$ & $\begin{array}{l}\mathrm{Cl} \\
95.0 \% \\
\text { for } \\
\\
\text { Odds } \\
\text { Ratio }\end{array}$ \\
\hline $\begin{array}{l}\text { Household with at least one member with a } \\
\text { chronic disease }\end{array}$ & 1.471 & 16.442 & $<0.0001$ & 4.354 & $\begin{array}{l}2.138- \\
8866\end{array}$ \\
\hline $\begin{array}{l}\text { Household with at least one member admitted to } \\
\text { a hospital for more than one night }\end{array}$ & 1.214 & 12.155 & $<0.0001$ & 3.367 & $\begin{array}{l}1.702- \\
6.663\end{array}$ \\
\hline Richest quintile (Reference group) & & 8.253 & 0.041 & & \\
\hline 2nd quintile & 0.066 & 0.013 & 0.908 & 1.069 & $\begin{array}{l}0.345- \\
3.310\end{array}$ \\
\hline 3rd quintile & 0.662 & 1.681 & 0.195 & 1.940 & $\begin{array}{l}0.713- \\
5.280\end{array}$ \\
\hline 4th quintile & 1.212 & 5.994 & 0.014 & 3.361 & $\begin{array}{l}1.273- \\
8.872\end{array}$ \\
\hline Household size $<5$ & 0.989 & 7.471 & 0.006 & 2.669 & $\begin{array}{l}1.321- \\
5.434\end{array}$ \\
\hline Distance to Provincial level hospital >10 & 1.566 & 8.689 & 0.003 & 4.587 & $\begin{array}{l}1.690- \\
13.560\end{array}$ \\
\hline Log likelihood & 234.767 & & & & \\
\hline Pseudo R2 & 0.147 & & & & \\
\hline \multirow[t]{2}{*}{ Hosmer-Lemeshow test } & $\begin{array}{l}x 2(8)= \\
10.074\end{array}$ & & & & \\
\hline & $P=0.260$ & & & & \\
\hline Observations & 314 & & & & \\
\hline
\end{tabular}

\section{Discussion}

Our study clarified the health-seeking behaviors, especially in chronic disease and related financial burdens of households in Bolikhamxay province, one of the provinces in Loa PDR fully covered by the current $\mathrm{NHI}$ system. Regarding the positive aspects of the $\mathrm{NHI}$, most patients (non-chronic $69.9 \%$, chronic $78.8 \%$ ) said that they visited a health facility for treatment. This study does not clarify whether this trend is an effect of the $\mathrm{NHI}$ because we did not have data from before NHI. Still, we highlight that in Bolikhamxay province, where the $\mathrm{NHI}$ has been implemented, more than $75 \%$ of the households in the relatively low-income household groups visited a health facility when one of the members had an illness, even though there are some gaps between income groups. Our study concurs with two past studies conducted in a different province [16-17] that found $\mathrm{NHI}$ has had positive impacts on access to health care. 
Nonetheless, this study also found financial problems for households under the current $\mathrm{NHI}$ scheme. We observed that $25 \%$ and $16 \%$ of the households with at least one member with any self-reported health problem were found to be experiencing CHE (20\%) and serious CHE (40\%) per month, respectively. Furthermore, $\mathrm{CHE}$ was more likely to occur in households with at least one member with a chronic disease and hospitalization. OOP health expenditure for chronic and severe diseases was found to be a big burden on households, especially poorer ones, and the design of future CHE prevention interventions need to take these factors into account [41-444]. Our findings indicate that the financial burden of households under the $\mathrm{NHI}$ remain high, especially when they have a member with a chronic and/or severe disease. Moreover, our analysis of sample demographics showed that even among households covered by the NHI system, the reality is that OOP health expenditure is greatly polarized between small payments (i.e., within the value covered by the $\mathrm{NHI}$ ) and very large payments (i.e., which greatly exceeds the value covered by the $\mathrm{NHI}$ ) among the households.

We offer the following reasons for these results. First, there are many households that prefer or may be forced to visit private facilities, because our result showed that households with members who used private facilities are more likely to face $\mathrm{CHE}$ than those who used only public facilities. A previous study confirms this assumption; it showed that people in Lao PDR preferred to utilize private health services as their first choice regardless of socioeconomic status, those with high socioeconomic status opted for private clinics and treatment abroad [45], and utilization of government services is low, with a high likelihood of an individual seeking care from a modern health provider when ill [46]. Another study found that many people from Lao PDR sometimes use health services from some Thailand provinces where most health workers speak Isan Thai (a dialect of the Lao language) as their native tongue [47]. Furthermore, our results demonstrated that a large percentage of the households chose to visit private facilities in foreign countries, even with $\mathrm{NHI}$ coverage. For these households, we hypothesize that the members may have diseases that are difficult to treat, or can only be treated in private facilities, or it could be that people still preferred to use a private facility even if costlier and not covered by NHI. Therefore, to avoid CHE in Lao PDR households covered by the $\mathrm{NHI}$, we see the need for stakeholders to ensure that effective treatment of these differential, and often more complex, patients can be provided at facilities covered by the NHI scheme. To achieve that, they need to find ways to attract the population and increase their willingness to visit public facilities, mainly by improving service quality and coverage in public hospitals.

Our results also showed that many households experienced $\mathrm{CHE}$ even at public hospitals. This may be due to the existence of additional costs related to visiting a health facility that go beyond those covered by the $\mathrm{NHI}$ co-payment scheme, including the indirect transportation costs. Previous research has also pointed out the existence of additional expenditures for patients visiting public health facilities, including those related to medications or supplies not available at the public health facilities or not covered by the NHI [47]. Thus, to prevent $\mathrm{CHE}$ among households covered by the $\mathrm{NHI}$, we see the need to expand the scope of the insurance coverage, especially for chronic patients (mainly those with NCDs), who require more complex and often prolonged treatments.

Among chronic patients in our sample, most visited the provincial, top referral hospital; importantly, there is only one such hospital in Bolikhamxay province. This denotes that travelling to the hospital entails a high 
cost (both time and money) for some households $[48,49]$. Coupled with the abovementioned CHE rate, this becomes a critical concern for stakeholders. For achieving UHC, primary care must be emphasized [50]. However, this emphasis in primary care may force patients to continue to suffer from complex and/or lifethreatening problems if they are not referred to higher level facilities; this is especially true of aging societies like that of Lao PDR $[51,52]$. These patients require advanced treatment, which often entails high costs and leads to CHE. Hence, we see the need for stakeholders to place additional focus on methods for providing $\mathrm{NHI}$ patients with advanced care while considering the realistic financial situation and the constraints of the NHI. The results of this study, which show that the groups in medical expenditure and ratio of medical expenditure to income are polarized, suggest the importance of supporting high medical expenditures. For example, in the Japanese $\mathrm{NHI}$, not only is there a fixed percentage (10\%-30\%) for copayments by treatment but also a maximum amount of total co-payment per month called "ceiling amount application" [53]. We advocate for a similar financial system for the NHI in Laos PDR, which may help prevent $\mathrm{CHE}$ among households with chronic patients.

To achieve UHC, it is important to enhance population and service coverage, as well as financial protection. In Lao PDR, the NHI was initially introduced with the aim of covering the entire population of the specific provinces in which it was implemented, as well as to provide financial protection through a fixed payment system. Nonetheless, this aim did not necessarily consider the enhancement of service provision; accordingly, we believe that the potential preventive effect of $\mathrm{NHI}$ on $\mathrm{CHE}$ was limited.

Even in poor households, it is common for people to seek better medical services when they become sick. Our findings underpin that CHE was more likely to occur in households with lower incomes. Similarly, global studies have highlighted the importance of ensuring a reasonable distribution of health services across different community-based and socioeconomic strata, especially for patients with chronic diseases [48]. Accordingly, our discussion suggests that the $\mathrm{NHI}$ requires additional improvements regarding health facility placement; patients especially need to be able to access reasonably located health facilities that deliver quality services. This is valid for facilities aimed at treating chronic patients, which often require long-term and frequent care delivery. To achieve UHC in Lao PDR, the government needs to take a comprehensive approach related to the $\mathrm{NHI}$ that better reflects its current situation.

This study has some limitations. First, we obtained information regarding household finance (i.e., health expenditure and income) by interviewing the household heads; this methodology may have affected data precision. Second, diagnoses based on self-reporting were included for those who did not visit a health facility, estimates (prevalence) were not weighted to obtain province-representative evidence, and a longitudinal design was not followed to assess the difference between pre- and post-NHI situations.

Nevertheless, to the best of our knowledge, this is the first study to investigate the health-seeking behaviors and financial burdens of households covered by the NHI in Lao PDR, including those with chronic patients. Most past studies related to the NHI in Lao PDR were conducted by targeting only patients who visited health facilities; their study design did not allow for collecting evidence from patients who did not visit or could not access a health facility. We felt it was important to understand the situation of households who did not/could not visit health facilities for assessing the effectiveness of interventions aimed at achieving 
UHC, such as the NHI in Lao PDR. This is because the main purpose of the NHI is to improve the general population's access to health facilities while ensuring they do not incur major financial burdens related to health care.

\section{Conclusion}

Our results provide a clear picture of the current status of the general population in provinces covered by the $\mathrm{NHI}$ regarding access to health services and their financial burden. We hope that this evidence provides a valuable theoretical framework for stakeholders and policymakers, who may use our data to conduct well-informed decision-making to facilitate the achievement of UHC in Lao PDR.

\section{Abbreviations}

NCDs: Non-communicable diseases

NHI: National Health Insurance

SDGs: Sustainable Development Goals

UHC: Universal health coverage

CHE: Catastrophic health expenditure

OOP: Out-of-pocket

\section{Declarations}

Ethics approval and consent to participate: This study was approved by both the National Center for Global Health and Medicine and the National Ethics Committee for Health Research of the Lao Ministry of Health. Verbal informed consent (approved by the Ethical Committee) was obtained from each respondent and key participant prior to commencing their respective interviews. All documents were de-identified. Caregivers or mothers provided consent for children when they took part in the interviews. Privacy and confidentiality were assured for all respondents.

Consent for publication: Not applicable.

Availability of data and materials: The data that support the findings of this study are available from the corresponding author upon reasonable request.

Competing interests: The authors declare that they have no competing interests.

\section{Funding:}

International Medical Research and Development Fund in National Center for Global Health and Medicine 
Project number: 28-3

Title of Research Project

Research on the use of overseas centers for health policy research on universal health coverage and other issues

Authors' contributions: Tomoo Ito was involved in study design, data analysis and interpretation. All authors critically revised the report, commented on drafts of the manuscript, and approved the final report.

\section{Acknowledgements:}

We are grateful to Dr. Khouanchay Soundavong

Dr Kethmany Chanthakouman and Lao TPHI team of data collectors for survey arrangement and data collection

\section{References}

[1] WHO. Systems financing - the path to universal

coverage. 2010. https://www.who.int/whr/2010/whr10_en.pdf. Accessed 1 Feb 2021.

[2] WHO. Universal health coverage (UHC). 2021. https://www.who.int/news-room/factsheets/detail/universal-health-coverage-(uhc). Accessed 1 Feb 2021.

[3] Kutzin J. Anything goes on the path to universal health coverage? No. Bull World Health Organ. 2012;90(11):867-68. doi:10.2471/BLT.12.113654.

[4] Behera M, Behera D. A critical analysis of the term “universal health coverage" under post-2015 Sustainable Development Goals. Ann Trop Med Public Health. 2015;8:155-158. [Google Scholar]

[5] International Labour Organization. (2008). Social health protect: an ILO strategy towards universal access to health care. 2008. https://www.ilo.org/wcmsp5/groups/public/--ed_protect/-soc_sec/documents/publication/wcms_secsoc_5956.pdf. Accessed 1 Feb 2021.

[6] WHO. Lao Ministry of Health moves forward with National Health Insurance. 2019. https://www.who.int/laos/news/detail/01-09-2019-lao-ministry-of-health-moves-forward-withnational-health-insurance. Accessed 30 Jun 2021.

[7] Patcharanarumol W, Mills A, Tangcharoensathien V. Dealing with the cost of illness: the experience of four villages in Lao PDR. J Inter Develop. 2009;21:212-30. doi:10.1002/jid.1549.

[8] GBD 2019 Diseases and Injuries Collaborators. Global burden of 369 diseases and injuries in 204 countries and territories, 1990-2019: a systematic analysis for the Global Burden of Disease Study 2019. Lancet. 2020;396(10258):1204-22. doi: 10.1016/S0140-6736(20)30925-9. 
[9] Nabel EG, Stevens S, Smith R. Combating chronic disease in developing countries. Lancet. 2009;373(9680):2004-06. doi:10.1016/S0140-6736(09)61074-6.

[10] Yach $D$, Kellogg $M$, Voute J. Chronic diseases: an increasing challenge in developing countries. Trans $R$ Soc Trop Med Hyg. 2005;99(5):321-4. doi:10.1016/j.trstmh.2005.02.001.

[11] Abegunde DO, Mathers CD, Adam T, Ortegon M, Strong K. The burden and costs of chronic diseases in low-income and middle-income countries. Lancet. 2007;370(9603):1929-38. doi: 10.1016/S01406736(07)61696-1.

[12] Pengpid S, Vonglokham M, Kounnavong S, Sychareun V, Peltzer K. The prevalence, awareness, treatment, and control of hypertension among adults: the first cross-sectional national population-based survey in Laos. Vasc Health Risk Manag. 2019;15:27-33. doi:10.2147/VHRM.S199178.

[13] Vonglokham M, Kounnavong S, Sychareun V, Pengpid S, Peltzer K. Prevalence and social and health determinants of pre-diabetes and diabetes among adults in Laos: a cross-sectional national populationbased survey, 2013. Trop Med Int Health. 2019;24(1):65-72. doi:10.1111/tmi.13164.

[14] Louangpradith V, Phoummalaysith B, Kariya T, Saw YM, Yamamoto E, Hamajima N. Disease frequency among inpatients at a tertiary general

hospital in Lao PDR. Nagoya J Med Sci. 2020;82:113-21. doi:10.18999/nagjms.82.1.113.

[15] Are C, Meyer B, Stack A, Ahmad H, Smith L, Qian B, Song T, Chowdhury S. Global trends in the burden of liver cancer. J Surg Oncol. 2017;115(5):591-602. doi:10.1002/jso.24518.

[16] Nagpal S, Masaki E, Pambudi ES, Jacobs B. Financial protection and equity of access to health services with the free maternal and child health initiative in Lao PDR. Health Policy Plan. 2019;34(Supplement_1):i14-i25.

doi:10.1093/heapol/czz077.

[17] The World Bank. Out-of-pocket spending and health service utilization in Lao P.D.R.: evidence from the Lao expenditure and consumption surveys (Policy Note). Lao PDR: World Bank; 2010.

[18] Lao Tourism Organization. Official website of Laos Tourism.

Available https://www.webcitation.org/6GagYn5rd?url=http://www.laotourism.org/laotourism.htm Accessed 30 Jun 2021.

[19] Japan International Cooperation Agency. Data collection survey on health sector in Lao People's Democratic Republic: Final report. 2016. Available from https://openjicareport.jica.go.jp/pdf/12252698_01.pdf. Accessed 1 Apr 2021

[20] Van Minh H, Phuong NTK, Saksena P, James CD, Xu K. Financial burden of household out-of-pocket health expenditure in Viet Nam: Findings from the National Living Standard Survey 2002-2010, Soc Sci 
Med. 2013;96:258-63. https://doi.org/10.1016/j.socscimed.2012.11.028.

[21] Lao Statistics Bureau, Ministry of Planning and Investment. Results of population and housing census 2015. 2015. https://www.familyplanning2020.org/sites/default/files/Lao-Population-census.pdf. Accessed 1 Apr 2021.

[22] Bernell S, Howard SW. Use your words carefully: what is a chronic disease? Front Public Health. 2016;4:159. doi:10.3389/fpubh.2016.00159.

[23]MedicineNet. Definition of Chronic Disease. (2016). http://www.medicinenet.com/script/main/art.asp? articlekey=33490 Accessed 11 Aug 2021

[24] Buigut S, Ettarh R, Amendah DD. Catastrophic health expenditure and its determinants in Kenya slum communities. Int J Equity Health. 2015;14:46. doi:10.1186/s12939-015-0168-9.

[25] Wyszewianski L. Financially catastrophic and high-cost cases: definitions, distinctions, and their implications for policy formulation. Inquiry. 1986;23(4):382-94.

[26] Berki SE. A look at catastrophic medical expenses and the poor. Health Aff (Millwood). 1986;5:138145. doi:10.1377/hlthaff.5.4.138.

[27] Xu K, Evans DB, Kawabata K, Zeramdini R, Klavus J, Murray CJL. Household catastrophic health expenditure: a multicountry analysis. Lancet. 2003;362(9378):111-7. doi:10.1016/S0140-6736(03)138615.

[28] Rashidian, A et al. Comparison of the thresholds of households' exposure to catastrophic health expenditure in Iran and Brazil, and selection of the most appropriate threshold." Iranian J Pub Health. 2018; 47,12:1945-1952.

[29] Aregbeshola BS, Khan SM. Determinants of catastrophic health expenditure in Nigeria. Eur J Health Econ. 2018;19:521-532.

[30] Buigut S, Ettarh R, Amendah DD. Catastrophic health expenditure and its determinants in Kenya slum communities. Int J Equity Health. 2015;14:46. https://doi.org/10.1186/s12939-015-0168-9,

[31] Brinda EM, Andrés RA, Enemark U. Correlates of out-of-pocket and catastrophic health expenditures in Tanzania: results from a national household survey. BMC Int Health Hum Rights. 2014;14:5. https://doi.org/10.1186/1472-698X-14-5

[32]. Kavosi Z, Rashidian A, Pourreza A, Majdzadeh R, Pourmalek M, Hosseinpour AR, Mohammad K, Mohammad A. Inequality in household catastrophic health care expenditure in a low-income society of Iran. Health Pol Plan. 2012;27:613-623. https://doi.org/10.1093/heapol/czs001

[33] Comprehensive Survey of Living Conditions https://www.mhlw.go.jp/english/database/dbhss/cslc.html 
[34] Health Measures in the 1997 Redesigned National Health Interview Survey (NHIS) https://www.cdc.gov/nchs/nhis/nhis_redesign.htm

[35] WHO Study of Global Ageing and Adult Health (SAGE)!

https://www.who.int/healthinfo/survey/SAGESurveyManualFinal.pdf

[36]Su TT, Kouyaté B, Flessa S. Catastrophic household expenditure for health care in a low-income society: a study from Nouna District, Burkina Faso. Bulletin of WHO 2006; 84,1:21-

27. https://doi.org/10.2471/BLT.05.023739.

[37] Wter HR, Anderson GF, Mays J. Measuring financial protection in health in the United States. Health Policy. 2004;69:339-49. https://doi.org/10.1016/j.healthpol.2004.01.003.

[38] Gotsadze G, Zoidze A, Rukhadze N. Household catastrophic health expenditure: evidence from Georgia and its policy implications. BMC Health Serv Res. 2009;9:69. https://doi.org/10.1186/1472-6963-9-69

[39] Greene W. Econometric analysis. 1997, New Jersey: Prentice Hall International Inc.

[40] Hosmer DW, Lemeshov S. Applied logistic regressions. 2000, New York. John Wiley \& Sons Inc.

[41] Choi JW, Kim, JH, et al. Association between chronic disease and catastrophic health expenditure in Korea. BMC Health Serv Res. 2015;15: 26. https://doi.org/10.1186/s12913-014-0675-

[42] Wang, Z, Li, X, Chen, M. Catastrophic health expenditures and its inequality in elderly households with chronic disease patients in China. Int J Equity Health. 2015;14:8. https://doi.org/10.1186/s12939-0150134-6

[43] Van Minh, H, Tran, BX Assessing the household financial burden associated with the chronic noncommunicable diseases in a rural district of Vietnam, Global Health Action 2012;5:1. https://doi.org/10.3402/gha.v5i0.18892

[44] Rezapour A, Vahedi S, Khiavi FF, Esmaeilzadeh F, Javan-Noughabi J, Rajabi A. Catastrophic health expenditure of chronic diseases: Evidence from Hamadan, Iran. Int J Prev Med.

2017;8:99. https://doi.org/10.4103/ijpvm.IJPVM_104_17

[45] Paphassarang C, Philavong K, Boupha B, Blas E. Equity, privatization and cost recovery in urban health care: the case of Lao PDR. Health Policy Plan. 2002; 17,1:72-84.

[46] Powell-Jackson T, Lindelow M. Out-of-pocket spending and health service utilization in Lao P.D.R.: Evidence from the Lao Expenditure and Consumption Surveys (Policy Note). 2010, Vientiane: World Bank, Lao P.D.R. Country Office

[47] Knowles JC. Public expenditure in the Lao PDR health sector: background paper for 2006 PER. Manila: Governance, Finance and Trade Division, Mekong Department, Asian Development Bank. 2006. 
[48] Fuady A, Houweling TAJ, Mansyur M. et al. Catastrophic total costs in tuberculosis-affected households and their determinants since Indonesia's implementation of universal health coverage. Infect Dis Poverty 2018;7:3. https://doi.org/10.1186/s40249-017-0382-3

[49] Barter DM, Agboola SO, Murray MB et al. Tuberculosis and poverty: the contribution of patient costs in sub-Saharan Africa - a systematic review. BMC Public Health. 2012;12: 980. https://doi.org/10.1186/14712458-12-980

[50] Primary health care on the road to universal health coverage. 2019 Global monitoring report executive summary, 2019. https://www.who.int/docs/default-source/documents/2019-uhc-report-executivesummary. Accessed 1 Jun 202

[51] Phouminidr B. Policy of ageing in Lao People's Democratic Republic. 2019. https://www.dukenus.edu.sg/docs/librariesprovider3/education-docs/1)-policies-on-the-health-of-older-adults-(laos)-byassociate-prof-dr-bouathep-phoumindr.pdf?sfvrsn=e3afdd71_4. Accessed 30 Jun 2021.

[52] WHO. Ageing and health in the South-East Asia Region. 2020.

https://www.who.int/southeastasia/health-topics/ageing. Accessed 1 Jun 2021.

[53] Ministry of Health, Labour and Welfare, Japan. High-cost medical expense benefit (Eligibility certificate for ceiling-amount application). https://www.mhlw.go.jp/file/06-Seisakujouhou-10800000Iseikyoku/0000056917.pdf. Accessed 1 Jun 2021.

\section{Figures}


Bolikhamsay province was selected because the National Health Insurance scheme has been implemented here.

Stage 1: Three districts were selected based on distance (in $\mathrm{km}$ ) from the provincial capital town:

1. The capital district (Pakxan),

2. The district $50 \mathrm{~km}$ from the capital district (Thaphabad)

3. The district $70-100 \mathrm{~km}$ from the capital district (Pakkading)

Stage 2: Five villages were selected in each district (one urban village, two rural villages with roads, and two rural without roads)

Stage 3: Selection of households was random (around 32-33 households in each village based on the village register book)

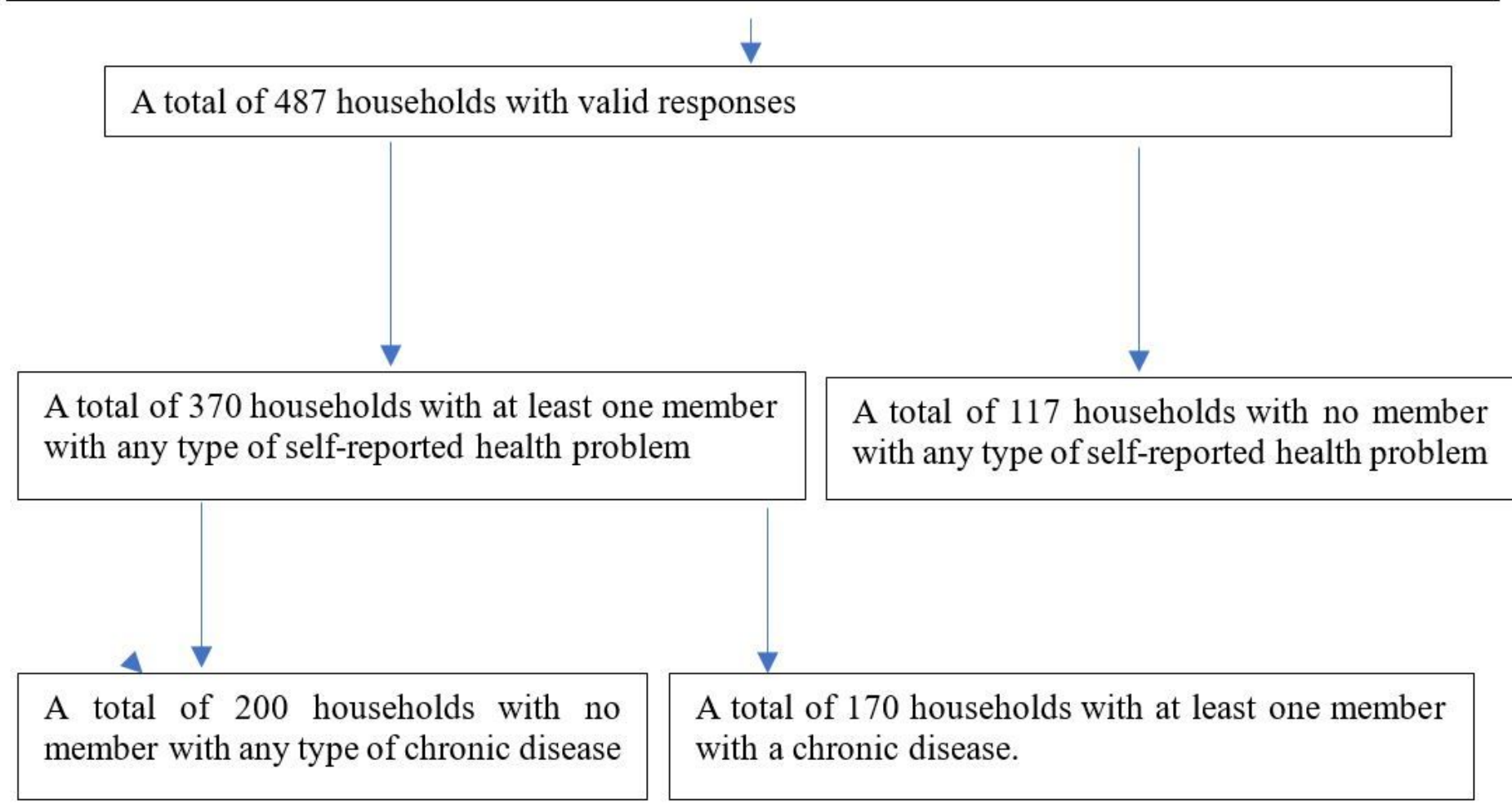

\section{Figure 1}

Flow of household sample selection 


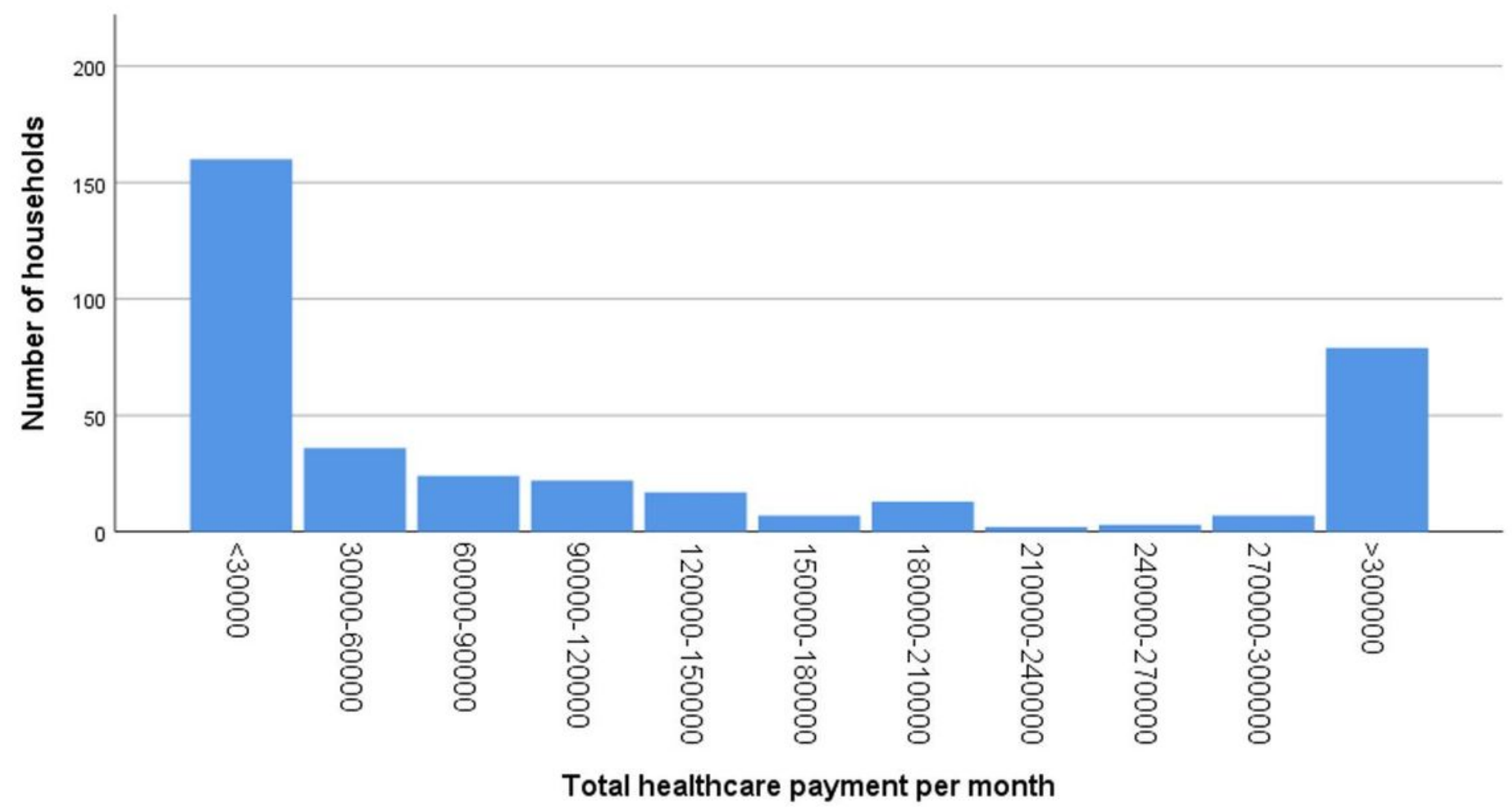

Figure 2

Distribution of household monthly health out-of-pocket expenditure. The distribution of total household monthly health expenditure is shown by each 30,000 LAK, until reaching a group that spent over 300,000 LAK. 


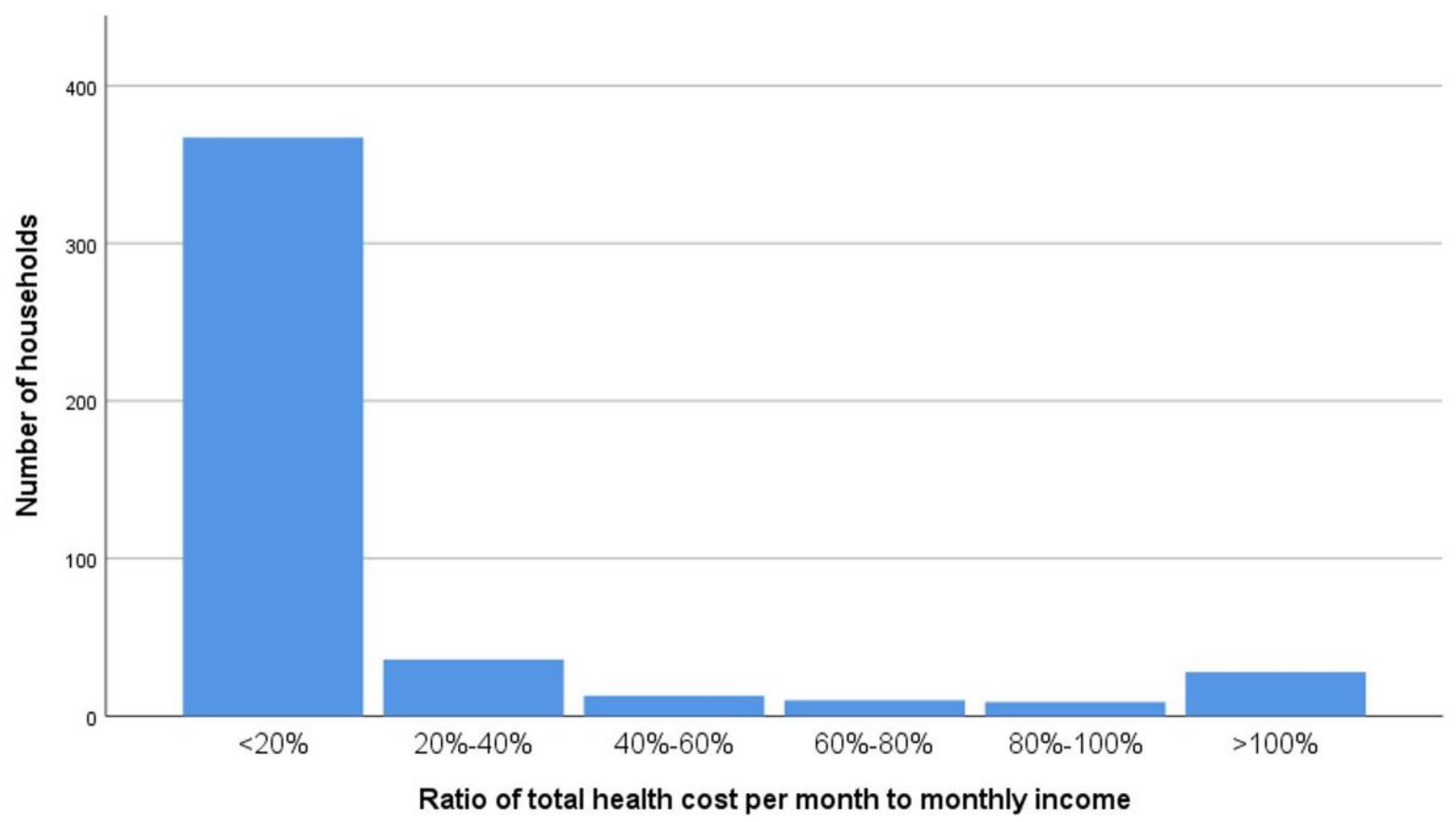

\section{Figure 3}

Distribution of households ratio of health out-of-pocket expenditure / income (\%). The distribution is shown by $20 \%$, until reaching a group that is over $100 \%$. 